\title{
Dispositivo para ensaio de resistência de aderência ao cisalhamento em revestimentos: desenvolvimento e validação
}

\author{
Shear bond strength device for mortar coatings: \\ development and validation
}

\section{Carina Mariane Stolz Angela Borges Masuero Ana Paula Kirchheim}

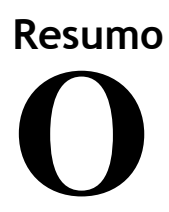

estudo da aderência de argamassas de revestimento torna-se importante quando se verifica a grande quantidade de manifestações patológicas presentes nas edificações devido aos descolamentos e desplacamentos. As principais propriedades que exercem influência no desenvolvimento da aderência são a resistência de aderência à tração, a resistência de aderência ao cisalhamento e a extensão de aderência, contudo a maioria dos estudos tem como foco apenas a resistência de aderência à tração. Nesse contexto, o presente trabalho apresenta um dispositivo desenvolvido para a realização de ensaios de resistência de aderência ao cisalhamento, que pode ser acoplado em um aderímetro comumente utilizado em ensaios de resistência de aderência à tração. Para a validação do dispositivo realizaram-se ensaios de resistência de aderência ao cisalhamento em três argamassas com diferentes teores de ar incorporado, aplicadas sobre substratos de concreto. Os resultados demonstram que o dispositivo desenvolvido é eficiente, de fácil utilização e reprodução, apresentando resultados de resistência de aderência ao cisalhamento coerentes e com baixos valores de coeficiente de variação, podendo tornar-se um importante equipamento para análise comparativa de argamassas.

Palavras-chaves: Aderência. Argamassa. Cisalhamento.

\section{Abstract}

Carina Mariane Stoltz Universidade Federal do Rio Grande do Sul Porto Alegre - RS - Brasil

Angela Borges Mausero Universidade Federal do Rio Grande Porto Alegre - RS - Brasil

Ana Paula Kirchheim Universidade Federal do Rio Grande do Sul Porto Alegre - RS - Brasil

Recebido em 17/08/15 Aceito em 19/05/16
The high incidence of building pathologies resulting from the lack of adherence of mortar coatings evidences the importance of conducting studies focusing on this problem. The main properties that influence adherence are tensile bond strength, shear bond strength and adherence extension or real interfacial contact area. However, most studies in this area focus only on tensile bond strength. In order to understand the properties that influence bond strength, it is essential to carry out interfacial mortar/substrate studies. Hence, this paper presentes an investigation of shear bond strength, the main property influencing the coating bond on mortars. A device to test shear bond strength was developed and tested. This tool can be fitted to a pull-off device that is commonly used and meets the Brazilian standards for tensile strength tests. In order to validate the proposed device, three different mortars with air-entraining admixture applied on concrete substrates were tested. The results showed that the device is effective and also easy to use and reproduce. The shear bond strength results were coherent and presented low variation coeficiente values, showing great potential for use in the comparative analysis of mortars.

Keywords: Shear bond strength. Mortar. Adherence. Shear device. 


\section{Introdução}

A NBR 13528 (ABNT, 2010, p. 1) define aderência como sendo a "[...] propriedade do revestimento de resistir às tensões atuantes na interface do substrato [...]". Diversos autores vêm estudando essa propriedade, destacando-se Carasek (1996), Sugo, Page e Lawrence (2001), Yates et al. (1994), Ramos et al. (2012), entre outros.

O desenvolvimento do mecanismo da aderência se dá em duas etapas distintas, consecutivas e intrinsecamente relacionadas: a adesão inicial e a aderência. A primeira ocorre no momento em que a argamassa no estado fresco é lançada sobre o substrato poroso; a segunda é a aderência propriamente dita, que se desenvolve ao longo do processo de hidratação dos aglomerantes da argamassa (MORENO JUNIOR; SELMO, 2007).

A adesão depende de vários fenômenos presentes na zona interfacial, como a molhabilidade do substrato, as forças de atração físicas induzidas no sistema, a geometria da superfície do substrato e o teor de umidade do substrato versus o tipo de material a ser assentado (GARBACZ; COURARD; KOSTANA, 2006). Bauer (2005) acrescenta que esse mecanismo de aderência instantânea da argamassa ao substrato no momento do lançamento é governado pela difusão e adsorção das moléculas de argamassa nas paredes dos poros do substrato e que a aderência final em si ocorre com o processo de enrijecimento da argamassa, no período em que a argamassa está à espera do sarrafeamento.

Carasek, Cascudo e Scartezini (2001) afirmam que a aderência da argamassa endurecida ao substrato é um fenômeno essencialmente mecânico, devido basicamente à penetração da pasta aglomerante ou da própria argamassa nos poros ou retida entre a rugosidade da base de aplicação. Segundo esses autores, quando a argamassa no estado plástico entra em contato com a superfície absorvente do substrato, parte da água de amassamento, que contém em dissolução ou estado coloidal os componentes do aglomerante, penetra pelos poros e cavidades desse substrato. No interior destes, ocorrem fenômenos de precipitação dos produtos de hidratação do cimento e da cal. Transcorrido algum tempo, com a cura, esses precipitados intracapilares exercem ação de ancoragem da argamassa à base.

Por outro lado, o assunto da ancoragem poderia ser eminentemente fruto da garantia de extensão de contato entre a rugosidade da base e o revestimento argamassado, conforme propõe Gonçalves (2004), quando afirma que o travamento mecânico, pela penetração do adesivo nas irregularidades do substrato, pode ser a força principal de atuação na aderência.

A aderência mecânica das argamassas ao substrato resulta da conjunção de três propriedades da interface argamassa-substrato atuantes no sistema (CARASEK; CASCUDO; SCARTEZINI, 2001; GONÇALVES, 2004):

(a) a resistência de aderência à tração, devido aos esforços normais gerados na utilização de um sistema de revestimento;

(b) a resistência de aderência ao cisalhamento, pelos esforços verticais e tangenciais ao revestimento gerados com a atuação da gravidade na argamassa aderida ao substrato; e

(c) a extensão de aderência, que evidencia a possível existência de falhas de contato com espaços vazios na interface.

Dessas propriedades, o ensaio de resistência de aderência à tração é o mais utilizado no contexto brasileiro e mundial para avaliação de revestimentos internos e externos, de argamassa ou cerâmico, nas edificações. No Brasil, esse ensaio é determinado através de método normalizado pela NBR 13528 (ABNT, 2010), no qual uma pastilha de $50 \mathrm{~mm}$ de diâmetro é colada sobre uma seção de argamassa previamente cortada, sendo isolada do restante do revestimento até ultrapassar $5 \mathrm{~mm}$ do substrato, e submetida, na sequência, a uma tensão de tração através de um equipamento mecânico ou hidráulico, registrando-se a tensão na qual ocorre a ruptura e a forma de ocorrência desta. Os resultados obtidos devem ser comparados com os limites especificados na NBR 13749 (ABNT, 2013), que estabelece os limites aceitáveis de resistência de aderência à tração para revestimentos de camada única e emboço.

A medição da extensão de aderência também não possui uma norma nacional ou internacional, no entanto alguns pesquisadores vêm propondo formas de quantificar as falhas de contato na interface argamassa-substrato. Nesse sentido, Ruduit (2009) quantificou áreas amostrais da interface através de imagens obtidas com lupa estereoscópica e quantificação da área de contato através de softwares computacionais. Stolz e Masuero (2015) quantificaram a extensão de aderência com o uso de digitalização tridimensional a laser e quantificação da área total interfacial com softwares computacionais.

Ao contrário do ensaio de resistência de aderência à tração, o ensaio de resistência de aderência ao cisalhamento não possui normalização no Brasil, 
bem como uma metodologia para a mensuração da área de contato. Apesar disso, é evidente que o esforço cisalhante gerado pela força da gravidade é muito relevante no desenvolvimento da adesão e da aderência dos sistemas de revestimento, podendo exercer grande influência no desempenho destes.

No âmbito internacional existem normas europeias que preconizam os ensaios de resistência de aderência ao cisalhamento, como a Réunion Internationale des Laboratoires d'Essais et de Recherches sur les Materiaux (Rilem), que propõe dois métodos para a medição da resistência de aderência ao cisalhamento, a MR-14 (RÉUNION..., 1982), "Determination of the Bond of renderings by shear tests", e a MR-20 (RÉUNION..., 1994), "Determination of the bond strenght of rendering by torsion test".

No meio técnico são encontrados poucos trabalhos que realizaram esse ensaio. Entre os averiguados pode-se citar Candia (1998) e Dubaj (2000). Este último foi executado mediante a utilização de um torquímetro, com base na norma Rilem MR-20 (RÉUNION..., 1994). Candia (1998) desenvolveu um dispositivo para a realização do ensaio de resistência de aderência ao cisalhamento direta, com a aplicação da força através de um braço de alavanca, o qual, para o autor, apresentou bom desempenho.

Nesse contexto, o presente trabalho tem como principal objetivo apresentar um dispositivo de fácil manuseio para a realização de ensaios de resistência de aderência ao cisalhamento em revestimentos de argamassa.

\section{Materiais e métodos}

O dispositivo para a realização do ensaio de resistência de aderência ao cisalhamento foi desenvolvido a partir de uma adaptação a um aderímetro, que possibilita o controle de aplicação de carga com precisão de leitura, além de ser um equipamento amplamente difundido no Brasil.

Para a validação do dispositivo proposto foi executado um programa experimental em que uma argamassa mista foi aplicada sobre substratos lisos de concreto.

Os substratos de concreto foram moldados nas dimensões de $25 \times 35 \times 5 \mathrm{~cm}$ e com resistência à compressão média de $35 \mathrm{MPa}$ aos 28 dias. Foram produzidos com cimento Portland CPII-Z e areia média de origem quartzosa (massa específica 2,50 $\mathrm{g} / \mathrm{cm}^{3}$ e módulo de finura 2,50), com proporcionamento realizado mediante dosagem pelo método do IPT/EPUSP (HELENE; TERZIAN, 1992), conforme a Tabela 1.
Sobre os substratos de concreto, curados durante 28 dias, foram aplicadas argamassas mistas com proporcionamento 1:1:3,10 (cimento:cal:areia, em massa), com fator água/aglomerante 1,2, variandose o percentual de aditivo incorporador de ar em sua composição em $0 \%$ (A1), $0,2 \%$ (A2) e $0,5 \%$ (A3) em relação à massa de cimento. A areia utilizada em sua produção foi de origem quartzosa, composta de $25 \%$ de cada uma das frações retidas nas peneiras 1,2, 0,6, 0,3 e 0,15 mm (massa específica $2,50 \mathrm{~g} / \mathrm{cm}^{3}$ e módulo de finura 3,19 ). Foi utilizada cal calcítica CHI e cimento Portland pozolânico CPIV. A escolha desse proporcionamento visou à obtenção de argamassas com diferentes comportamentos reológicos e resistências mecânicas elevadas, de modo que os ensaios de resistência de aderência fornecessem o máximo de resultados com ruptura na interface argamassa-substrato.

A caracterização dos cimentos e da cal utilizados encontra-se nas Tabelas 2 e 3 respectivamente.

A aplicação da argamassa sobre o substrato de concreto foi realizada com a utilização de um dispositivo denominado "caixa de queda", mantendo-se a altura de lançamento constante em $1 \mathrm{~m}$, de forma a obter-se controle quanto à energia de aplicação.

Nesse programa experimental não se utilizou a camada de chapisco propositalmente, para avaliar a interação argamassa-substrato sem nenhum tipo de preparo.

Aos 28 dias de cura realizaram-se ensaios de resistência de aderência ao cisalhamento (Rc), através do dispositivo desenvolvido, além de ensaios de controle tecnológico da argamassa e concreto do substrato, através de ensaios físicos e mecânicos, conforme as normas brasileiras.

Os Rc foram executados com o dispositivo desenvolvido acoplado ao aderímetro, da marca Pavitest, com resolução de 0,1 MPa e leitor digital.

O número de amostras para cada sistema de revestimento (tipo de substrato e tipo de argamassa) respeitou o número mínimo de 12 corpos de prova, preconizado pela NBR 13528 (ABNT, 2010), sendo necessários dois substratos de concreto de $25 \mathrm{~cm}$ x $30 \mathrm{~cm}$ para essa quantidade de amostras ( 6 corpos de prova em cada substrato). Considerando-se que foi avaliado um substrato de concreto com três argamassas diferentes aplicadas sobre ele, foram moldados 6 substratos de concreto, totalizando 72 corpos de prova para o ensaio de Rc. 


\section{Apresentação e discussão dos resultados}

\section{Dispositivo desenvolvido}

A seguir estão apresentados croquis do dispositivo desenvolvido.

A Figura 1 ilustra as vistas superior e lateral do dispositivo com as respectivas cotas (em $\mathrm{mm}$ ). Ressalta-se que o "ponto sobressalente" (identificado pelo detalhe "A") presente no equipamento deve ser dimensionado de forma que o centro de força seja aplicado na mesma linha da interface argamassa-substrato a ser ensaiada.
A pastilha fixada na extremidade do dispositivo (identificada na Figura 1 pelo detalhe "B") deve ser compatível ao equipamento de tração utilizado para a aplicação da carga cisalhante.

Para apoiar o aderímetro foi desenvolvido um suporte com duas peças. Uma delas, mostrada na Figura 2, apoia o aderímetro (peça 1), e a outra, mostrada na Figura 3, trava a primeira peça no substrato (peça 2).

A Figura 4 apresenta o corte perpendicular do corpo de prova a ser ensaiado e a aplicação dessas duas peças, e a Figura 5 apresenta fotografias do dispositivo no momento da execução de um ensaio.

Tabela 1 - Proporcionamento do concreto utilizado na confecção dos substratos

\begin{tabular}{|c|c|c|c|c|c|c|c|c|c|}
\hline \multirow{2}{*}{$\begin{array}{c}\text { Dosagem } \\
\text { (traço) }\end{array}$} & \multirow[b]{2}{*}{$\alpha(\%)$} & \multicolumn{3}{|c|}{ Proporcionamento } & \multicolumn{3}{|c|}{ Propriedades } & \multirow{2}{*}{$\begin{array}{c}\text { Consumo } \\
\text { cimento }\left(\mathrm{kg} / \mathrm{m}^{3}\right)\end{array}$} & \multirow{2}{*}{$\begin{array}{l}\text { Consumo de } \\
\text { água }\left(\mathrm{L} / \mathrm{m}^{3}\right)\end{array}$} \\
\hline & & cim & $\mathbf{a}$ & p & $\mathbf{a} / \mathbf{c}$ & $\mathrm{H}(\%)$ & slump $(\mathbf{c m})$ & & \\
\hline $1: 3,73$ & 56 & $\overline{1}$ & 1,65 & 2,08 & 0,47 & 9,94 & $10 \pm 2$ & 461 & 216,67 \\
\hline
\end{tabular}

Tabela 2 - Características químicas e físicas dos cimentos empregados

\begin{tabular}{|c|c|c|c|c|c|c|c|c|c|}
\hline Cimento & $\begin{array}{c}\text { Perda } \\
\text { ao } \\
\text { fogo } \\
(\%)\end{array}$ & $\begin{array}{c}\text { MgO } \\
(\%)\end{array}$ & $\begin{array}{l}\mathrm{SO}_{3} \\
(\%)\end{array}$ & $\begin{array}{l}\mathrm{CO}_{2} \\
(\%)\end{array}$ & $\begin{array}{c}\text { Resíduo } \\
\text { insolúvel } \\
(\%)\end{array}$ & $\begin{array}{c}\text { Equivalente } \\
\text { alcalino em } \\
\mathrm{Na}_{2} \mathrm{O}-(0,658 \times \\
\left.\mathrm{K}_{2} \mathrm{O} \%+\mathrm{Na}_{2} \mathrm{O} \%\right) \\
(\%)\end{array}$ & $\begin{array}{c}\text { Massa } \\
\text { específica } \\
\left(\mathrm{g} / \mathrm{cm}^{3}\right)\end{array}$ & $\begin{array}{c}\text { Superficie } \\
\text { específica } \\
\text { Blaine } \\
\left(\mathbf{m}^{3} / \mathbf{k g}\right)\end{array}$ & $\begin{array}{c}\text { Finura } \\
\text { da } \\
\text { peneira } \\
\# 200\end{array}$ \\
\hline CP II Z & 5,29 & 4,72 & 2,42 & & 26,17 & 1,49 & 2,95 & 489,63 & 3,4 \\
\hline CP IV 32 & 3,18 & 5,79 & 3,01 & 4,51 & 11,5 & 0,7 & 2,67 & 459 & 1,1 \\
\hline
\end{tabular}

Tabela 3 - Características químicas e físicas da cal empregada

\begin{tabular}{|c|c|c|c|}
\hline Descrição & Ensaios realizados $(\%)$ & $\begin{array}{c}\text { Limites (\%) } \\
\text { NBR 6473/03 }\end{array}$ & Metodologia \\
\hline $\begin{array}{c}\mathrm{CaO} \text { total } \\
\mathrm{MgO} \text { total } \\
\text { Massa específica } \\
\text { Diâmetro médio }\end{array}$ & $\begin{array}{c}67,26 \\
4,02 \\
2,28 \mathrm{~g} / \mathrm{cm}^{3} \\
9,03 \mu \mathrm{m}\end{array}$ & $\begin{array}{l}55 \text { mínimo } \\
29 \text { máximo }\end{array}$ & $\begin{array}{c}\text { FRX } \\
\text { FRX } \\
\text { NBR NM } 23(\text { ABNT, 2000) } \\
\text { Laser }\end{array}$ \\
\hline
\end{tabular}

Figura 1 - Detalhamento do dispositivo (cotas em $\mathrm{mm}$ )
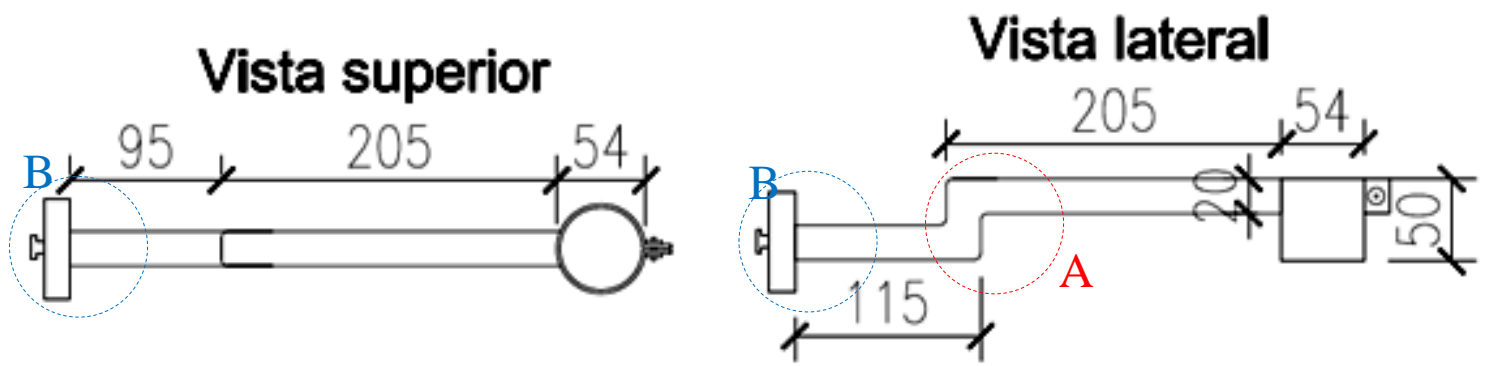

188 Stolz, C. M.; Masuero, A. B.; Kirchheim, A. P. 
Figura 2 - Detalhamento da peça 1 (cotas em mm)

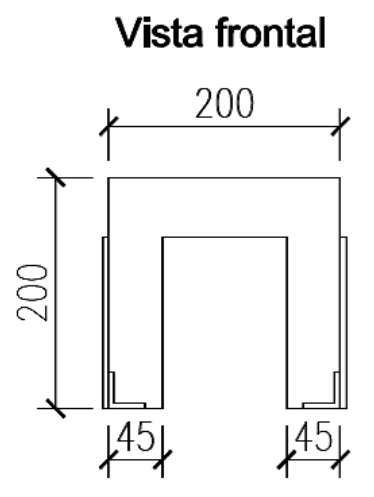

\section{Vista lateral}

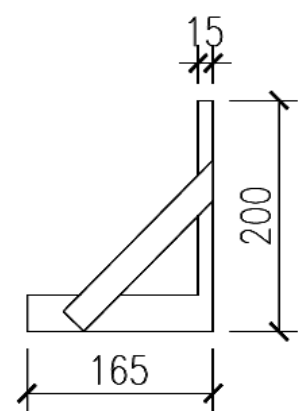

Vista superior

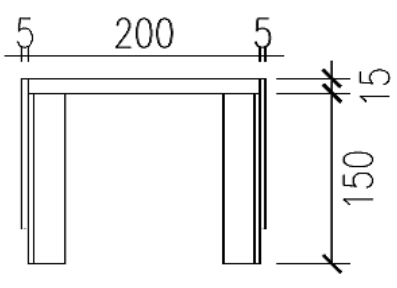

Figura 3 - Detalhamento da peça 2 (cotas em $\mathrm{mm}$ )

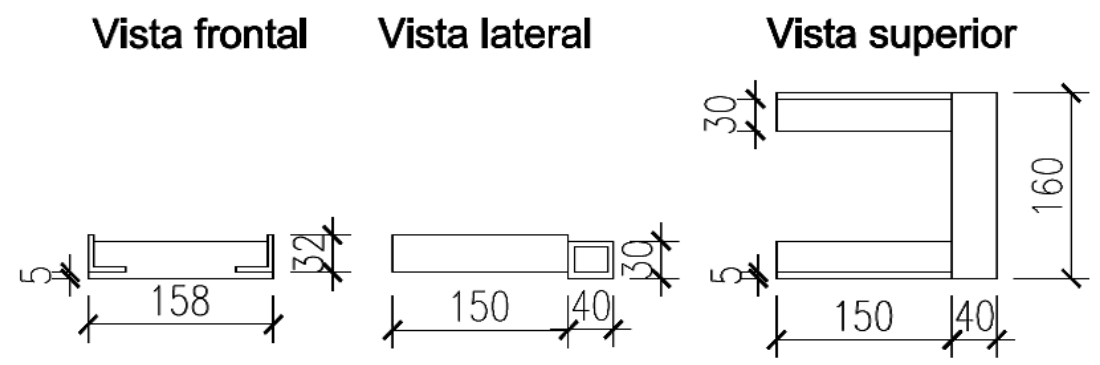

Figura 4 - Corte apresentando a aplicação do dispositivo para a execução do ensaio de resistência ao cisalhamento

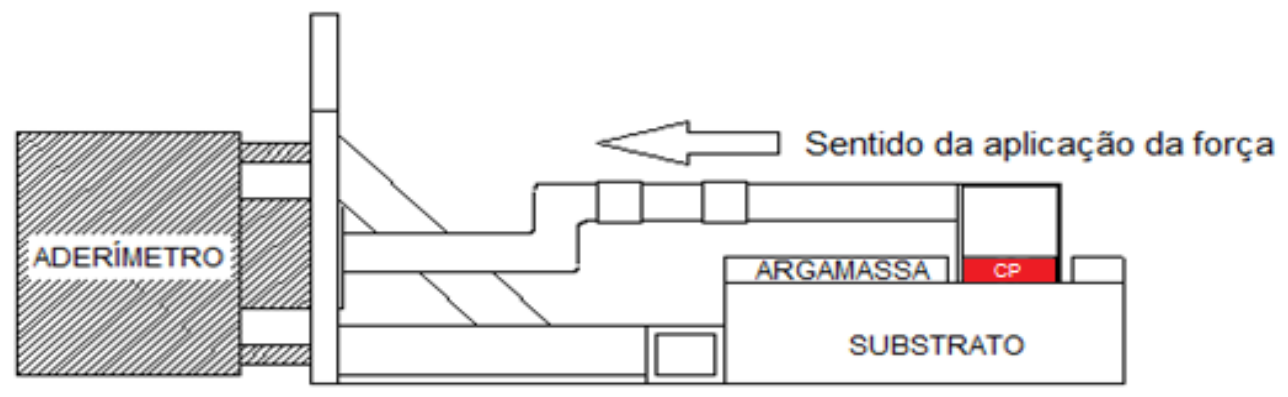

Figura 5 - (a) Vista lateral e (b) superior do dispositivo no momento da execução do ensaio

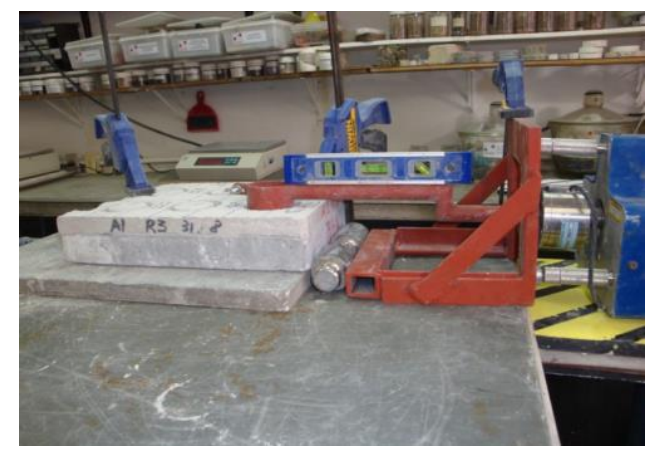

(a)

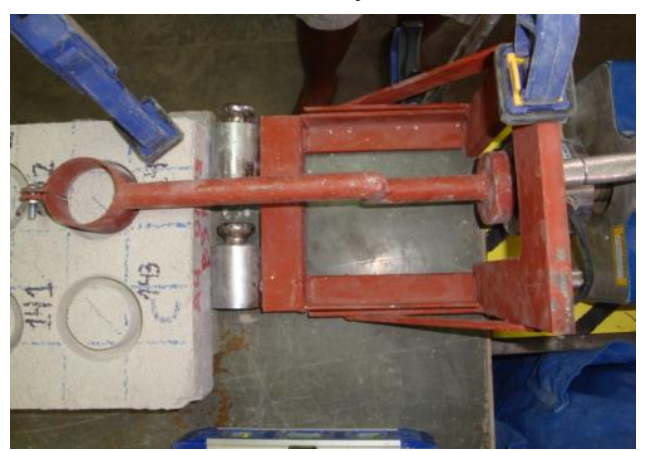

(b) 
O dispositivo foi desenvolvido de forma que a força cisalhante fosse aplicada na interface argamassa-substrato (Figura 6a). No entanto, em caso de necessidade de análise do comportamento de todo o sistema de revestimento quanto ao cisalhamento, pode ser realizada uma adaptação, conforme a Figura 6b. Quando se desejar avaliar todo o sistema de revestimento, deve-se aplicar a carga cisalhante no topo do corpo de prova, através da colagem de uma pastilha metálica igual ou semelhante à utilizada na realização do ensaio de resistência de aderência à tração.

Para garantir que a carga seja aplicada paralelamente ao substrato a ser analisado, sem a formação de uma força de momento, é fundamental o nivelamento do dispositivo de cisalhamento, bem como do aderímetro acoplado a ele. Esse nivelamento deve ser realizado antes da aplicação da carga, com a utilização de nível de bolha.

É muito importante que tanto o dispositivo quanto a amostra a ser ensaiada estejam muito bem fixos sobre a mesa ou bancada onde as amostras estiverem apoiadas, para uma correta realização do ensaio. Esse travamento deve evitar que tanto o dispositivo quanto o sistema de revestimento (substrato + argamassa) façam movimento de giro, o que pode provocar alterações na carga aplicada sobre o corpo de prova, com a aplicação de um momento fletor na região ensaiada. Tal travamento pode ser realizado com o uso de sargentos e/ou grampos.

\section{Considerações sobre o preparo do corpo de prova}

Para a execução do ensaio com o dispositivo desenvolvido foram tomados alguns cuidados com o preparo dos corpos de prova.
Cabe destacar que as dimensões utilizadas para o desenvolvimento desse dispositivo foram definidas com base nas espessuras do substrato e da argamassa utilizadas neste trabalho, de $5 \mathrm{~cm}$ e 2 $\mathrm{cm}$ respectivamente. Portanto, para sua reprodução em substratos e revestimentos com espessuras diferentes dessas, algumas adaptações deverão ser realizadas.

Para proporcionar área livre suficiente para o deslizamento do dispositivo na horizontal, aplicando uma tensão de cisalhamento no corpo de prova, foi necessário realizar o corte dos corpos de prova utilizando-se de duas serras-copo de dimensões diferentes. Primeiramente foi realizado o corte com uma serra copo de $60 \mathrm{~mm}$ de diâmetro, e posteriormente com uma de $70 \mathrm{~mm}$ de diâmetro. O resíduo de argamassa que restou entre os cortes realizados foi totalmente removido, evitando a permanência de obstáculos que poderiam travar o deslizamento do dispositivo e tomando-se muito cuidado para não danificar o corpo de prova. Realizado esse procedimento, foi produzido um espaço de aproximadamente $10 \mathrm{~mm}$ entre o corpo de prova e as paredes do restante do revestimento, espaço suficiente para o deslizamento do dispositivo.

O aspecto do corpo de prova após o corte com a serra-copo de $60 \mathrm{~mm}$ de diâmetro e após o corte com as serras-copo de $60 \mathrm{~mm}+70 \mathrm{~mm} \mathrm{de}$ diâmetro está apresentado na Figura 7.

Os cortes foram realizados em uma serra de bancada buscando-se perpendicularidade. A Figura 8 apresenta a serra de bancada (a) utilizada para a realização dos cortes, bem como as serras-copo utilizadas na realização deles (b).

Figura 6 - Força cisalhante aplicada (a) na interface argamassa-substrato (b) na superfície do sistema de revestimento

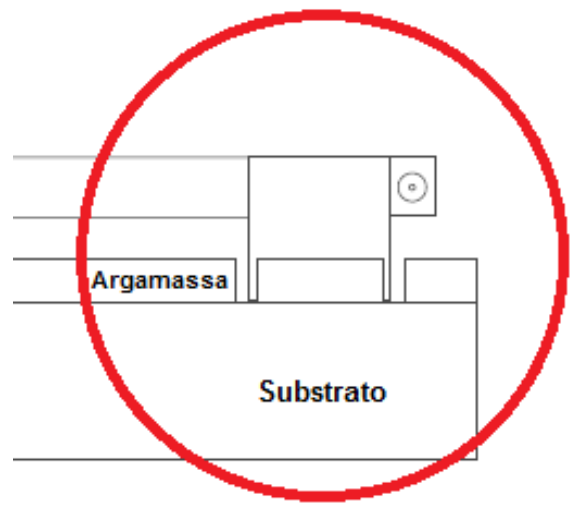

(a)

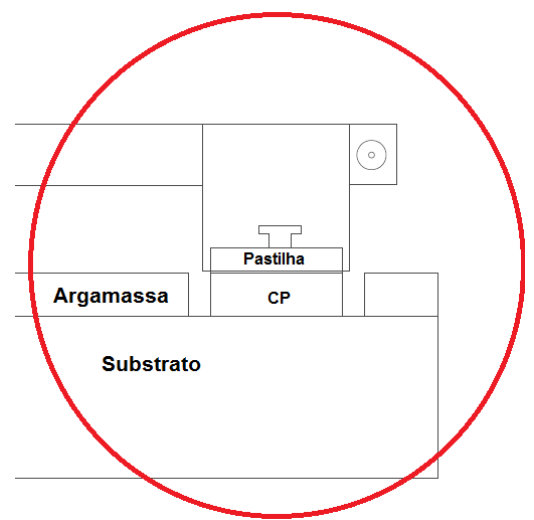

(b)

190 Stolz, C. M.; Masuero, A. B.; Kirchheim, A. P. 
Figura 7 - Representação do aspecto do corpo de prova cortado pelas duas serras-copo utilizadas

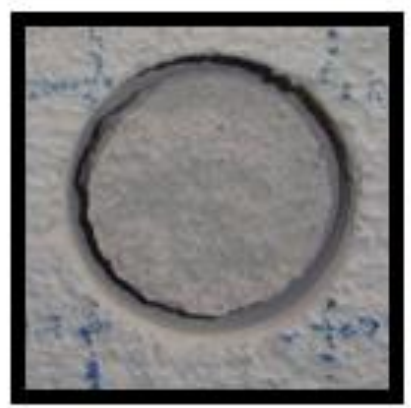

$\Phi 60 \mathrm{~mm}$

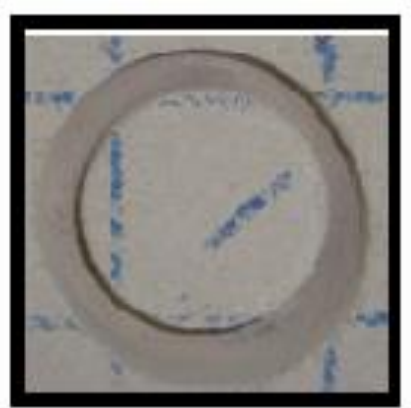

$\Phi 60 \mathrm{~mm}+\Phi 70 \mathrm{~mm}$

Figura 8 - Recursos para o preparo do corpo de prova. a) serra de bancada; b) vista frontal das serrascopo para a realização do corte

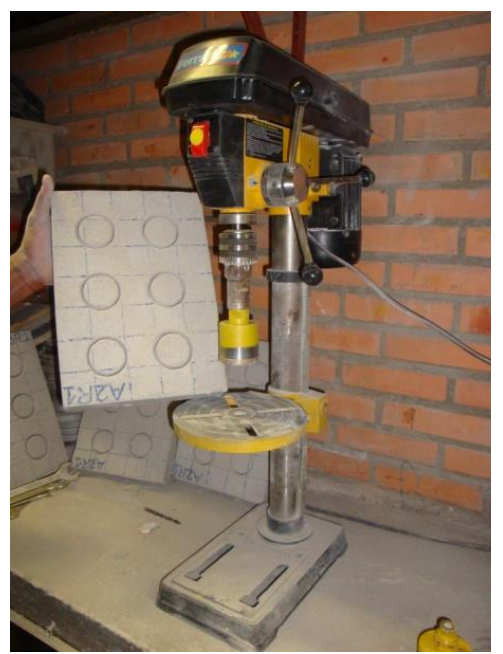

(a)

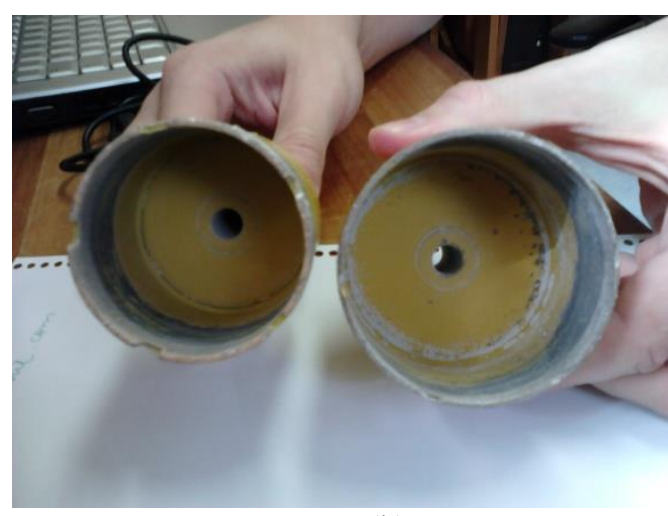

(b)

\section{Resultados de validação do dispositivo}

A Tabela 4 apresenta os resultados da caracterização das argamassas estudadas. Os ensaios no estado endurecido foram realizados aos 28 dias de idade dos corpos de prova.

Em geral, as características físicas e mecânicas das argamassas apresentaram resultados dentro do esperado. Os ensaios apresentaram comportamento diretamente influenciado pelo teor de ar incorporado nas argamassas.

No estado fresco, o aumento do teor de ar resultou em aumento no índice de consistência das argamassas, indicativo de melhora na trabalhabilidade, além de redução na densidade de massa, pela maior presença de bolhas de ar na mistura. Quanto à retenção de água, a maior presença de vazios resultantes do aditivo incorporador de ar nas argamassas parece ter facilitado a saída de água da mistura, reduzindo a 
retenção de água, mesmo comportamento encontrado por Do Ó (2004) ao avaliar argamassas com diferentes teores de ar incorporado em sua composição.

O comportamento dos ensaios no estado fresco teve influência direta no desempenho no estado endurecido. Quanto maior foi a porcentagem de aditivo incorporador de ar nas argamassas, menores foram os valores de densidade de massa e, consequentemente, de resistência mecânica. Esse comportamento também foi obtido no estudo de Alves (2002), que atribuiu a redução da resistência mecânica de argamassas com aditivo incorporador de ar ao aumento dos vazios nas argamassas.

Figura 9 - Exemplo de ensaio realizado em corpo de prova sem espaço suficiente para o deslizamento horizontal do dispositivo ao aplicar a tensão de cisalhamento
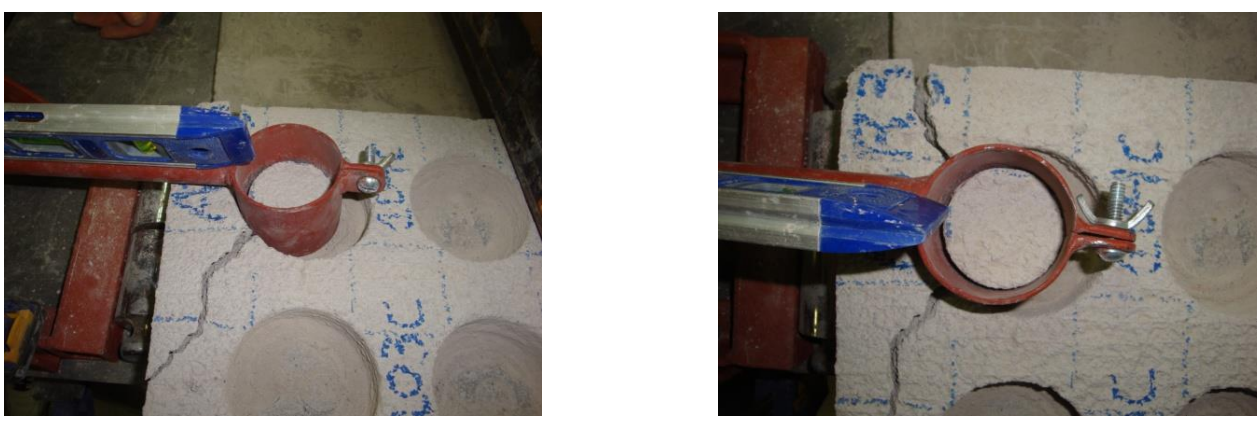

Tabela 4 - Características físicas e mecânicas das argamassas

\begin{tabular}{|c|c|c|c|c|c|c|}
\hline Ensaio & Norma & Argamassa & $\begin{array}{l}\text { Resultado } \\
\text { médio }\end{array}$ & $\begin{array}{l}\text { Desvio } \\
\text { padrão }\end{array}$ & $\begin{array}{c}\text { Coef. de } \\
\text { variação } \\
(\%)\end{array}$ & $\begin{array}{c}\text { Classificação } \\
\text { NBR 13281 } \\
\text { (ABNT, } \\
\text { 2005c) }\end{array}$ \\
\hline $\begin{array}{l}\text { Índice de } \\
\text { consistência }\end{array}$ & $\begin{array}{c}\text { NBR } 13276 \\
(\mathrm{ABNT}, 2002 \mathrm{a})\end{array}$ & $\begin{array}{l}\text { A1 } \\
\text { A2 } \\
\text { A3 }\end{array}$ & $\begin{array}{l}272 \mathrm{~mm} \\
284 \mathrm{~mm} \\
288 \mathrm{~mm}\end{array}$ & $\begin{array}{l}1,17 \mathrm{~mm} \\
1,50 \mathrm{~mm} \\
0,85 \mathrm{~mm}\end{array}$ & $\begin{array}{l}0,43 \\
0,53 \\
0,29\end{array}$ & \\
\hline $\begin{array}{l}\text { Densidade de } \\
\text { massa no } \\
\text { estado fresco }\end{array}$ & $\begin{array}{c}\text { NBR } 13278 \\
(\mathrm{ABNT}, 1995)\end{array}$ & $\begin{array}{l}\text { A1 } \\
\text { A2 } \\
\text { A3 }\end{array}$ & $\begin{array}{l}1.639 \mathrm{~kg} / \mathrm{m}^{3} \\
1.536 \mathrm{~kg} / \mathrm{m}^{3} \\
1.446 \mathrm{~kg} / \mathrm{m}^{3}\end{array}$ & $\begin{array}{l}96,78 \mathrm{~kg} / \mathrm{m}^{3} \\
20,82 \mathrm{~kg} / \mathrm{m}^{3} \\
15,10 \mathrm{~kg} / \mathrm{m}^{3}\end{array}$ & $\begin{array}{l}5,91 \\
1,36 \\
1,04 \\
\end{array}$ & \\
\hline $\begin{array}{l}\text { Teor de ar } \\
\text { incorporado }\end{array}$ & $\begin{array}{c}\text { NBR NM } 47 \\
(\mathrm{ABNT}, 2002 \mathrm{~b})\end{array}$ & $\begin{array}{l}\text { A1 } \\
\text { A2 } \\
\text { A3 }\end{array}$ & $\begin{array}{l}2,65 \% \\
4,90 \% \\
6,45 \%\end{array}$ & $\begin{array}{l}0,07 \% \\
0,00 \% \\
0,35 \%\end{array}$ & $\begin{array}{l}2,67 \\
0,00 \\
5,48\end{array}$ & \\
\hline $\begin{array}{l}\text { Retenção de } \\
\text { água }\end{array}$ & $\begin{array}{c}\text { NBR } 13277 \\
(\mathrm{ABNT}, 2005 \mathrm{a})\end{array}$ & $\begin{array}{l}\text { A1 } \\
\text { A2 } \\
\text { A3 }\end{array}$ & $\begin{array}{l}96 \% \\
84 \% \\
79 \% \\
\end{array}$ & $\begin{array}{l}1,85 \% \\
0,37 \% \\
0,05 \% \\
\end{array}$ & $\begin{array}{l}1,92 \\
0,45 \\
0,07 \\
\end{array}$ & $\begin{array}{l}\mathrm{U} 5 \\
\mathrm{U} 3 \\
\mathrm{U} 2\end{array}$ \\
\hline $\begin{array}{c}\text { Coef. de } \\
\text { absorção de } \\
\text { água por } \\
\text { capilaridade }\end{array}$ & $\begin{array}{c}\text { NBR } 15259 \\
(\mathrm{ABNT}, 2005 \mathrm{~d})\end{array}$ & $\begin{array}{l}\text { A2 } \\
\text { A3 }\end{array}$ & $\begin{array}{c}9,43 \\
\mathrm{~g} / \mathrm{dm}^{2} \cdot \min 1 / 2 \\
9,26 \\
\mathrm{~g} / \mathrm{dm}^{2} \cdot \min ^{1} 1 / 2 \\
9,13 \\
\mathrm{~g} / \mathrm{dm}^{2} \cdot \min ^{1} / 2\end{array}$ & $\begin{array}{c}1,97 \\
\mathrm{~g} / \mathrm{dm}^{2} \cdot \min ^{1} 1 / 2 \\
1,24 \\
\mathrm{~g} / \mathrm{dm}^{2} \cdot \min ^{1} 1 / 2 \\
0,96 \\
\mathrm{~g} / \mathrm{dm}^{2} \cdot \min ^{1 / 2}\end{array}$ & $\begin{array}{l}20,89 \\
13,39 \\
10,51\end{array}$ & $\begin{array}{l}\mathrm{C} 5 \\
\mathrm{C} 5 \\
\mathrm{C} 5\end{array}$ \\
\hline $\begin{array}{l}\text { Densidade de } \\
\text { massa no } \\
\text { estado } \\
\text { endurecido }\end{array}$ & $\begin{array}{c}\text { NBR } 13279 \\
(\mathrm{ABNT}, 2005 \mathrm{~b})\end{array}$ & $\begin{array}{l}\text { A1 } \\
\text { A2 } \\
\text { A3 }\end{array}$ & $\begin{array}{l}1857 \mathrm{~kg} / \mathrm{m}^{3} \\
1728 \mathrm{~kg} / \mathrm{m}^{3} \\
1657 \mathrm{~kg} / \mathrm{m}^{3}\end{array}$ & $\begin{array}{l}18,42 \mathrm{~kg} / \mathrm{m}^{3} \\
15,23 \mathrm{~kg} / \mathrm{m}^{3} \\
20,62 \mathrm{~kg} / \mathrm{m}^{3}\end{array}$ & $\begin{array}{l}0,99 \\
0,88 \\
1,24\end{array}$ & $\begin{array}{l}\text { M5 } \\
\text { M4 } \\
\text { M4 }\end{array}$ \\
\hline $\begin{array}{l}\text { Resistência à } \\
\text { compressão }\end{array}$ & $\begin{array}{c}\text { NBR } 13279 \\
(\mathrm{ABNT}, 2005 \mathrm{~b})\end{array}$ & $\begin{array}{l}\text { A1 } \\
\text { A2 } \\
\text { A3 }\end{array}$ & $\begin{array}{l}7,08 \mathrm{MPa} \\
5,19 \mathrm{MPa} \\
3,52 \mathrm{MPa} \\
\end{array}$ & $\begin{array}{l}2,52 \mathrm{MPa} \\
0,76 \mathrm{MPa} \\
0,51 \mathrm{MPa} \\
\end{array}$ & $\begin{array}{l}35,59 \\
14,57 \\
14,49 \\
\end{array}$ & $\begin{array}{l}\text { P5 } \\
\text { P4 } \\
\text { P3 }\end{array}$ \\
\hline $\begin{array}{l}\text { Resistência à } \\
\text { tração na } \\
\text { flexão }\end{array}$ & $\begin{array}{c}\text { NBR } 13279 \\
(\mathrm{ABNT}, 2005 \mathrm{~b})\end{array}$ & $\begin{array}{l}\text { A1 } \\
\text { A2 } \\
\text { A3 }\end{array}$ & $\begin{array}{l}1,28 \mathrm{MPa} \\
1,14 \mathrm{MPa} \\
0,90 \mathrm{MPa}\end{array}$ & $\begin{array}{l}0,33 \mathrm{MPa} \\
0,13 \mathrm{MPa} \\
0,10 \mathrm{MPa}\end{array}$ & $\begin{array}{l}25,43 \\
11,46 \\
10,65\end{array}$ & $\begin{array}{l}\text { R2 } \\
\text { R1 } \\
\text { R1 }\end{array}$ \\
\hline
\end{tabular}

192 Stolz, C. M.; Masuero, A. B.; Kirchheim, A. P. 
A absorção de água por capilaridade parece não ter sofrido tanto a influência das bolhas de ar, já que estas influenciam mais diretamente nos poros fechados internamente à argamassa, evitando gerar maior quantidade de poros capilares. Alves (2002) também não conseguiu observar correlação entre o teor de ar e a absorção capilar das argamassas estudadas por ela.

Os valores de resistência de aderência ao cisalhamento estão apresentados na Tabela 5. Destaca-se que os valores grifados foram considerados espúrios e retirados da análise estatística. Foram também considerados espúrios todos os valores compreendidos acima ou abaixo da média dos doze valores obtidos mais o desvio padrão e a média dos doze valores obtidos menos o desvio padrão.

Através dos resultados de resistência de aderência ao cisalhamento obtidos, considera-se que o equipamento desenvolvido apresentou resultados satisfatórios, visto que as médias dos valores de Rc diminuíram com o aumento do teor de aditivo incorporador de ar presente na argamassa. Esses resultados são coerentes ao serem comparados com as características físicas das argamassas no estado, tendo argamassas com maior teor de ar incorporado e menores resistências mecânicas apresentado comportamento inferior quanto à aderência.

Esse mesmo comportamento foi observado por Alves (2002) para ensaios de resistência de aderência à tração. A autora sugere que essa diminuição na resistência de aderência ocorre devido à redução da superfície de contato entre a argamassa e o substrato em função da presença de bolhas de ar na interface e pela perda de resistência mecânica da argamassa, principalmente devido à perda de compacidade do material. Ainda, o aumento das bolhas de ar reduz a resistência mecânica das argamassas, o que possibilita maior fragilidade ao sistema, com rupturas na argamassa com menores cargas.

Outro aspecto importante observado foi o coeficiente de variação (CV) obtido para os ensaios realizados. Verifica-se que esse coeficiente apresentou valores de até $25 \%$, considerado aceitável quando comparado com ensaios de resistência de aderência à tração que tem como característica intrínseca alto coeficiente de variação. Segundo Gonçalves (2004), é comum se observar um coeficiente de variação da ordem de $50 \%$ nos resultados desses ensaios.

$\mathrm{O}$ aumento do coeficiente de variação com o aumento da concentração de aditivo incorporador de ar nas argamassas, observado nos resultados desta pesquisa, pode ser explicado pela variação de desempenho observada em argamassas com maiores teores de aditivo incorporador de ar em sua composição, anteriormente citado por Recena (2007).

Tabela 5 - Resistência de aderência ao cisalhamento $(\mathrm{Rc})$ aos 28 dias de idade, obtida para as três argamassas estudadas

\begin{tabular}{|c|c|c|c|c|c|c|c|c|c|c|c|}
\hline \multicolumn{4}{|c|}{ A1 } & \multicolumn{4}{|c|}{ A2 } & \multicolumn{4}{|c|}{ A3 } \\
\hline \multirow[t]{2}{*}{ Rc (MPa) } & \multicolumn{2}{|c|}{$\begin{array}{c}\text { Forma de } \\
\text { ruptura }(\%)\end{array}$} & \multirow{2}{*}{$\begin{array}{c}\text { Umidade } \\
(\%)\end{array}$} & \multirow{2}{*}{$\begin{array}{c}\text { Rc } \\
(\mathbf{M P a})\end{array}$} & \multicolumn{2}{|c|}{$\begin{array}{c}\text { Forma de } \\
\text { ruptura }(\%)\end{array}$} & \multirow{2}{*}{$\begin{array}{c}\text { Umidade } \\
(\%)\end{array}$} & \multirow{2}{*}{$\begin{array}{c}\mathbf{R c} \\
(\mathbf{M P a})\end{array}$} & \multicolumn{2}{|c|}{$\begin{array}{c}\text { Forma de } \\
\text { ruptura }(\%)\end{array}$} & \multirow{2}{*}{$\begin{array}{l}\text { Umidade } \\
(\%)\end{array}$} \\
\hline & Sub/Arg & Arg & & & Sub/Arg & Arg & & & Sub/Arg & Arg & \\
\hline 0,95 & 100 & & 4,17 & 0,39 & 95 & 5 & 3,48 & 0,35 & 90 & 10 & 3,50 \\
\hline 0,42 & 100 & & 4,21 & 0,52 & 95 & 5 & 3,52 & 0,23 & 100 & & 3,59 \\
\hline 0,89 & 100 & & 4,27 & 0,53 & 90 & 10 & 3,52 & 0,29 & 100 & & 3,38 \\
\hline 0,67 & 100 & & 4,09 & 0,44 & 80 & 20 & 3,47 & 0,34 & 100 & & 3,61 \\
\hline 0,66 & 80 & 20 & 4,12 & 0,42 & 100 & & 3,45 & 0,26 & 100 & & 3,50 \\
\hline 0,59 & 100 & & 4,03 & 0,40 & 90 & 10 & 3,43 & 0,23 & 100 & & 3,56 \\
\hline 0,85 & 100 & & 4,54 & 0,61 & 85 & 15 & 3,29 & 0,12 & 100 & & 3,40 \\
\hline 0,40 & 100 & & 4,49 & 0,45 & 90 & 10 & 3,38 & 0,16 & 100 & & 3,47 \\
\hline 0,59 & 100 & & 4,57 & 0,74 & 90 & 10 & 3,38 & 0,24 & 100 & & 3,35 \\
\hline 0,48 & 100 & & 4,51 & 0,61 & 90 & 10 & 5,58 & 0,56 & 100 & & 3,46 \\
\hline 0,48 & 100 & & 4,43 & 0,58 & 100 & & 3,30 & 0,12 & 100 & & 3,32 \\
\hline 0,75 & 100 & & 4,31 & 0,41 & 100 & & 3,36 & 0,19 & 100 & & 3,41 \\
\hline \multicolumn{2}{|c|}{$\begin{array}{l}\text { Desvio padrão } \\
\text { (MPa): }\end{array}$} & 0,10 & & \multicolumn{2}{|c|}{$\begin{array}{l}\text { Desvio padrão } \\
\text { (MPa): }\end{array}$} & 0,08 & & \multicolumn{2}{|c|}{$\begin{array}{l}\text { Desvio padrão } \\
\text { (MPa): }\end{array}$} & 0,06 & \\
\hline \multicolumn{2}{|c|}{ CV (\%): } & 16,52 & & \multicolumn{2}{|c|}{ CV (\%): } & $\begin{array}{c}16,9 \\
1\end{array}$ & & \multicolumn{2}{|c|}{ CV (\%): } & 24,73 & \\
\hline \multicolumn{2}{|c|}{ Média (MPa): } & 0,60 & & \multicolumn{2}{|c|}{ Média (MPa): } & 0,50 & & \multicolumn{2}{|c|}{ Média (MPa): } & 0,25 & \\
\hline
\end{tabular}

Nota: *os valores grifados foram considerados espúrios e excluídos da análise. 


\section{Conclusões}

A partir dos resultados obtidos pode-se considerar que o dispositivo desenvolvido é de fácil manuseio e de baixo custo, podendo ser facilmente difundido no meio técnico.

Comparando-se o dispositivo desenvolvido com o desenvolvido por Candia (1998), pode-se constatar que o dispositivo aqui proposto é mais compacto, o que facilita seu manuseio, transporte e operação. No entanto, o dispositivo desenvolvido por Candia (1998) permite a execução do ensaio em revestimentos aplicados em paredes, na vertical, situação que exigiria uma adaptação para a aplicação do dispositivo desenvolvido neste trabalho, desenvolvido para aplicações em sistemas de revestimento produzidos em corpos de prova de tamanho reduzido e em laboratório (miniparedes).

Comparando-se o dispositivo desenvolvido nesta pesquisa com o ensaio de cisalhamento com a utilização do torquímetro (RÉUNION..., 1994), pode-se afirmar que aquele reproduz com maior fidelidade os esforços verticais decorrentes da gravidade exercida no revestimento, enquanto o torquímetro simula a tensão cisalhante com esforços aplicados na forma de torque (giro).

Por fim, mesmo com a variabilidade inerente de argamassas com aditivo incorporador de ar em sua composição, os resultados de resistência de aderência ao cisalhamento encontrados nesta pesquisa foram coerentes. Quanto maior a porcentagem de aditivo incorporador de ar nas argamassas, menores foram os valores de resistência de aderência à tração.

Complementarmente, os coeficientes de variação encontrados podem ser considerados baixos quando comparados aos obtidos em ensaios de resistência de aderência ao cisalhamento presentes na bibliografia.

Dessa forma, considera-se validado o dispositivo desenvolvido, adequado para a realização de ensaios de resistência de aderência ao cisalhamento em laboratório, com aplicação de carga controlada através do acoplamento ao aderímetro e com a possibilidade de se realizarem adaptações conforme a espessura e as camadas que se deseja ensaiar em cada tipo de sistema de revestimento que se deseje avaliar.

\section{Referências}

\author{
ALVES, N. J. D. Avaliação dos Aditivos \\ Incorporadores de Ar em Argamassas de \\ Revestimento. Brasília, 2002. 199 f. Dissertação \\ (Mestrado em Engenharia Civil) - Escola de \\ Engenharia, Universidade de Brasília, Brasília, \\ 2002.
}

\section{ASSOCIAÇÃO BRASILEIRA DE NORMAS \\ TÉCNICAS. NBR 13276: argamassa para} assentamento de paredes e tetos: preparo da mistura e determinação do índice de consistência. Rio de Janeiro, 2002a.

\section{ASSOCIAÇÃO BRASILEIRA DE NORMAS \\ TÉCNICAS. NBR 13277: argamassa para} assentamento e revestimento de paredes e tetos: determinação da retenção de água. Rio de Janeiro, $2005 \mathrm{a}$

\section{ASSOCIAÇÃO BRASILEIRA DE NORMAS \\ TÉCNICAS. NBR 13278: argamassa parra} assentamento de paredes e tetos: determinação da densidade de massa e do teor de ar incorporado. Rio de Janeiro, 1995

\section{ASSOCIAÇÃO BRASILEIRA DE NORMAS \\ TÉCNICAS. NBR 13279: argamassa parra} assentamento de paredes e tetos: determinação da resistência à tração na flexão e à compressão. Rio de Janeiro, 2005b

\section{ASSOCIAÇÃO BRASILEIRA DE NORMAS}

TÉCNICAS. NBR 13281: argamassa para assentamento e revestimento de paredes e tetos requisitos. Rio de Janeiro, 2005c.

\section{ASSOCIAÇÃO BRASILEIRA DE NORMAS}

TÉCNICAS. NBR 13528: revestimento de paredes e tetos de argamassas inorgânicas: determinação da resistência de aderência à tração. Rio de Janeiro, 2010.

\section{ASSOCIAÇÃO BRASILEIRA DE NORMAS}

TÉCNICAS. NBR 13749: revestimento de paredes e tetos de argamassas inorgânicas: especificação. Rio de Janeiro, 2013.

\section{ASSOCIAÇÃO BRASILEIRA DE NORMAS}

TÉCNICAS. NBR 15259: argamassa para assentamento e revestimento de paredes e tetos: determinação da absorção de água por capilaridade e do coeficiente de capilaridade. Rio de Janeiro, $2005 \mathrm{~d}$.

\section{ASSOCIAÇÃO BRASILEIRA DE NORMAS}

TÉCNICAS. NM 23: cimento portland e outros materiais em pó: determinação da massa específica. Rio de Janeiro, 2000. 
ASSOCIAÇÃO BRASILEIRA DE NORMAS TÉCNICAS. NM 47: concreto: determinação do teor de ar em concreto fresco: método pressométrico. Rio de Janeiro, 2002b.

BAUER, E. Revestimentos de Argamassa: características e peculiaridades. Brasília: LEMUnB; Sinduscon, 2005.

CANDIA, M. C. Contribuição ao Estudo das Técnicas de Preparo da Base no Desempenho dos Revestimentos de Argamassa. São Paulo, 1998. 198 f. Tese (Doutorado em Engenharia Civil) - Escola Politécnica, Universidade de São Paulo, São Paulo, 1998.

CARASEK, H. Aderência de Argamassas à Base de Cimento Portland a Substratos Porosos: avaliação dos fatores intervenientes e contribuição ao estudo do mecanismo de ligação. São Paulo, 1996. 285 f. Tese (Doutorado em Engenharia Civil) - Escola Politécnica, Universidade de São Paulo, São Paulo, 1996.

CARASEK, H.; CASCUDO, O.; SCARTEZINI, L. M. Importância dos Materiais na Aderência dos Revestimentos de Argamassa. In: SIMPÓSIO BRASILEIRO DE TECNOLOGIA DAS ARGAMASSAS, 4., Brasília, 2001. Anais... Brasília: SBTA, 2001.

DO Ó, S. W. Análise da Retenção de Água em Argamassas de Revestimento Aditivadas. Brasília, 2004. 173 f. Dissertação (Mestrado em Engenharia Civil) - Escola de Engenharia, Universidade de Brasília, Brasília, 2004.

DUBAJ, E. Estudo Comparativo Entre Traços de Argamassa de Revestimento Utilizadas em Porto Alegre. Porto Alegre, 2000. 115 f. Dissertação (Mestrado em Engenharia Civil) Escola de Engneharia, Universidade Federal do Rio Grande do Sul, Porto Alegre, 2000.

GARBACZ, A.; COURARD, L.; KOSTANA, K. Characterization of Concrete Surface Roughness and Its Relation to Adhesion in Repair Systems. Materials Caracterization, v. 56, n. 4, p. 281289, 2006.

GONÇALVES, S. R. C. Variabilidade e Fatores de Dispersão da Resistência de Aderência nos Revestimentos de Argamassa: estudo de caso. Brasília, 2004. 148 f. Dissertação (Mestrado em Engenharia Civil) - Escola de Engenharia, Universidade de Brasília, Brasília, 2004.
HELENE, P. R. L.; TERZIAN, P. R. Manual de dosagem e controle do concreto. Brasília: Pini, 1992.

MORENO JUNIOR, R.; SELMO, S. M. de S. Aderência de Argamassas de Reparo de Estruturas de Concreto. São Paulo, 2007. Boletim técnico da escola politécnica da USP.

RAMOS, N. M. M. et al. Reliability of the PullOff Test in Situ Evaluation of Adhesion Strength. Construction and Building Materials, v. 31, p. 86-93, 2012.

RECENA, F. A. P. Conhecendo Argamassa. Porto Alegre: Edipucrs, 2007.

\section{RÉUNION INTERNATIONAL DES}

LABORATOIRES D'ESSAIS ET MATÉRIAUX. MR 14: recommendations for the Testing and Use of Constructions Materials: determination of the bond of renderings by shear tests. Paris, 1982.

\section{RÉUNION INTERNATIONAL DES}

LABORATOIRES D'ESSAIS ET MATÉRIAUX.

MR 20: recommendations for the testing and use of constructions materials: determination of the bond strenght of rendering by torsion test. Paris, 1994.

RUDUIT, F. R. Influência da Cura de Chapiscos na Aderência em Substratos de Concreto. Porto Alegre, 2009. 177 f. Dissertação (Mestrado em Engenharia Civil) - Escola de Engenharia, Universidade Federal do Rio Grande do Sul, Porto Alegre, 2009.

STOLZ, C. M.; MASUERO, A. B. Analysis of Main Parameters Affecting Substrate/Mortar Contact Area Through Tridimensional Laser Scanner. Journal of Colloid and Interface Science, v. 455, p. 16-23, 2015.

SUGO, H. O.; PAGE, A. W.; LAWRENCE, S. J. The Development of Mortar/Unit Bond. In: CANADIAN MASONRY SYMPOSIUM, 9., Fredericton, 2001. Proceedings... Fredericton, 2001.

YATES, M. et al. The Importance of the Porosity of Mortars, Tiles and Bricks in Relation to Their Bonding Strengths. Studies in surface science and catalysis, v. 87, p. 781-190, 1994.

\section{Agradecimentos}

Os autores agradecem à Capes e ao CNPq, pelo apoio financeiro através de bolsa de mestrado, e à equipe do Norie/PPGEC/UFRGS, pelo apoio à pesquisa. 


\section{Carina Mariane Stoltz}

Departamento de Engenharia Civil, Escola de Engenharia | Universidade Federal do Rio Grande do Sul | Av. Osvaldo Aranha, $99,3^{\circ}$ andar, Bom Fim | Porto Alegre - RS - Brasil | CEP 90035-190 | Tel.: (51) 3308-3518 | E-mail: carimstolz@yahoo.com.br

Angela Borges Mausero

Departamento de Engenharia Civil, Escola de Engenharia | Universidade Federal do Rio Grande do Sul | E-mail: angela.masuero@ufrgs.br

Ana Paula Kirchheim

Departamento de Engenharia Civil, Escola de Engenharia | Universidade Federal do Rio Grande do Sul | E-mail: anapaula.k@ufrgs.br

\section{Revista Ambiente Construído}

Associação Nacional de Tecnologia do Ambiente Construído

Av. Osvaldo Aranha, $99-3^{\circ}$ andar, Centro

Porto Alegre - RS - Brasil

CEP 90035-190

Telefone: +55 (51) 3308-4084

Fax: +55 (51) 3308-4054

www.seer.ufrgs.br/ambienteconstruido

E-mail: ambienteconstruido@ufrgs.br

196 Stolz, C. M.; Masuero, A. B.; Kirchheim, A. P. 